\title{
Article \\ Adaptive On-Time Control Buck Converter with a Novel Virtual Inductor Current Circuit
}

\author{
Hsiao-Hsing Chou ${ }^{1}{ }^{(0)}$, Hsin-Liang Chen ${ }^{2}$, Yang-Hsin Fan $\left.{ }^{3} \mathbb{(}\right)$ and San-Fu Wang ${ }^{4, *}$ \\ 1 Department of Electrical Engineering, National Penghu University of Science and Technology, \\ Penghu 880011, Taiwan; hankchou36@gms.npu.edu.tw \\ 2 Department of Electrical Engineering, Chinese Culture University, Taipei 11114, Taiwan; \\ cxl7@ulive.pccu.edu.tw \\ 3 Department of Computer Science and Information Engineering, National Taitung University, \\ Taitung 95092, Taiwan; yhfan@nttu.edu.tw \\ 4 Department of Electronic Engineering, National Chin-Yi University of Technology, Taichung 411030, Taiwan \\ * Correspondence: sf_wang@ncut.edu.tw; Tel.: +886-4-2392-4505-7315
}

check for updates

Citation: Chou, H.-H.; Chen, H.-L.; Fan, Y.-H.; Wang, S.-F. Adaptive On-Time Control Buck Converter with a Novel Virtual Inductor Current Circuit. Electronics 2021, 10, 2143. https://doi.org/10.3390/

electronics10172143

Academic Editor: Khaled Ahmed

Received: 29 July 2021

Accepted: 29 August 2021

Published: 3 September 2021

Publisher's Note: MDPI stays neutral with regard to jurisdictional claims in published maps and institutional affiliations.

Copyright: (c) 2021 by the authors. Licensee MDPI, Basel, Switzerland. This article is an open access article distributed under the terms and conditions of the Creative Commons Attribution (CC BY) license (https:// creativecommons.org/licenses/by/ $4.0 /)$.

\begin{abstract}
This study presents a new virtual inductor current circuit to reduce circuit complexity, which is not necessary to sense inductance current directly. The buck converter was designed to produce an output voltage of 1.0-2.5 V for a 3.0-3.6 V input voltage. The load current range was from $100 \mathrm{~mA}$ to $500 \mathrm{~mA}$. It was simulated and verified by SIMPLIS and MathCAD. The simulation results of this buck converter show that the voltage error is within $1 \%$, and the recovery time is smaller than $2 \mu$ s for step-up and step-down load transients. Additionally, it achieves less than $26 \mathrm{mV}$ overshoot at full-load step transient response. The circuit topology would be able to fabricate using TSMC $0.35 \mu \mathrm{m}$ 2P4M CMOS technology. The control mechanism, implementation, and design procedure are presented in this paper.
\end{abstract}

Keywords: virtual inductor current (VIC); adaptive ON time (AOT); constant ON time (COT); electromagnetic interference (EMI); discontinuous conduction mode (DCM); pulse-width modulation (PWM)

\section{Introduction}

Nowadays, the DC-DC buck converter is widely used in mobile phones and other portable electronic devices [1]. In order to improve the competitiveness of products, these portable devices often have more functions, but it also means more power consumption. The power supply of these devices is the battery. Reducing the power consumption of electronic devices can increase the standby time. Therefore, high conversion efficiency and fast response are the key points of power management design [2]. At present, in the power conversion technology, the control mode is roughly divided into voltage mode [3] and current mode [4-8]. As can be seen from Figure 1a, the voltage mode is single-loop control-the voltage loop [3]. In contrast, in Figure 1b, the current mode is dual-loop control-a voltage loop and a current loop. Compared to voltage mode, the current mode has more feedback paths from inductance current; therefore, the current mode has a faster transient response and better voltage regulation than the voltage mode. Therefore, current mode control is widely used in power management IC. With the above two control modes, there are many new control topologies that have been proposed to achieve high speed, low power, high efficiency, and small size. For example, constant on-time (COT) control technology or adaptive on-time (AOT) control technology is used in many converters.

COT control has a feature of high light-load efficiency [9-11]. COT control is a variablefrequency control. Under the discontinuous conduction mode (DCM), the switching frequency is naturally lowered, and the efficiency is higher; while the switching frequency increases during the load transient or voltage tracking. The variable switching frequency 
will affect the overall conversion efficiency due to the switching and conduction losses. The main disadvantage of the COT control scheme is the limitation of the duty cycle. The ON time always follows the preset minimum off time, which depends on the power stage and control logic. This causes the maximum duty cycle to be limited by the $\mathrm{ON}$ time during load transient.

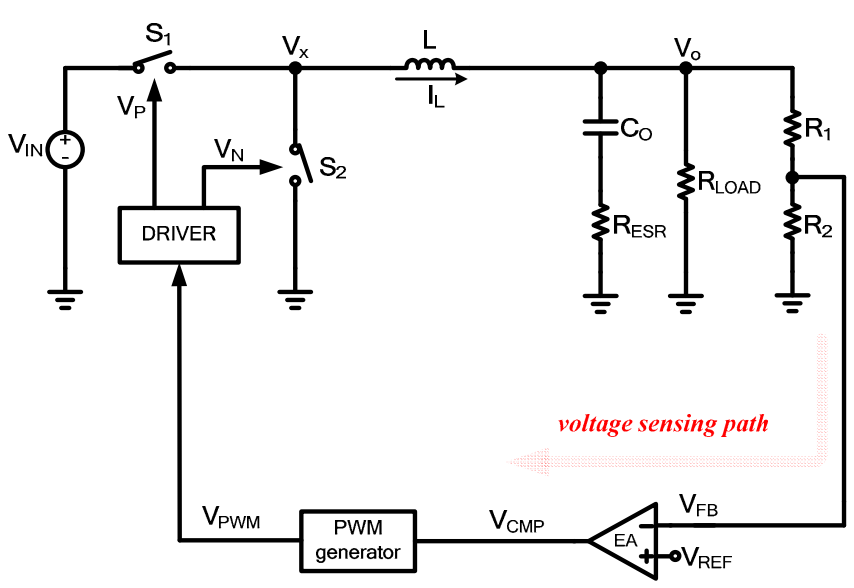

(a) Conventional voltage-mode control

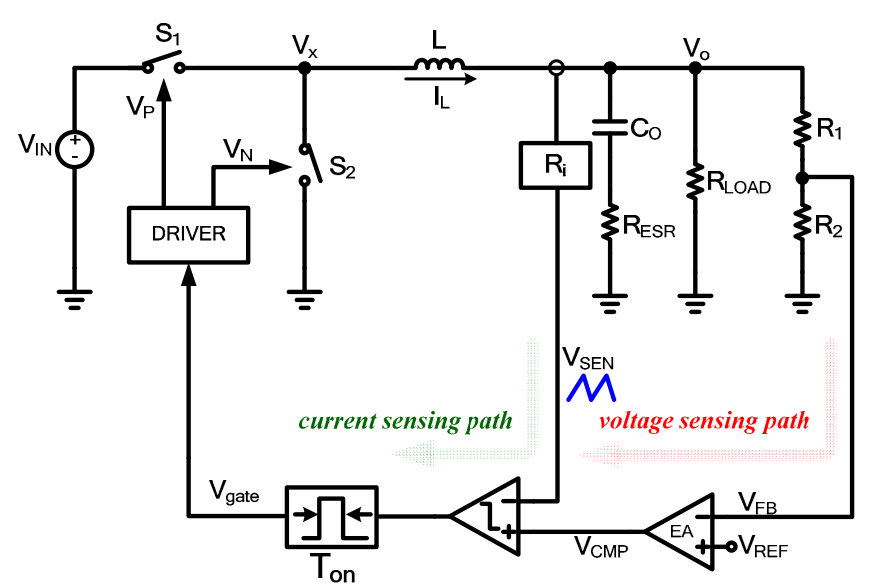

(b) Conventional current-mode control

Figure 1. Voltage-/current-mode control schemes.

Although the variable switching frequency can improve the efficiency in DCM, it will also make the other blocks in the system hard to control the electromagnetic interference (EMI) [12-14]. Since the operation principle of the switching power converter is to control the switch on/off, the EMI of the converter is inevitable.

In contrast, in Reference [15], the ON time is designed in inverse/direct proportional to input/output voltage to realize virtually constant-frequency operation, which is known as adaptive on-time (AOT) control. The conventional AOT control scheme is shown in Figure 2. The adaptive on-time control can improve the frequency instability of the COT control. Moreover, there is no subharmonic oscillation issue in AOT current-mode control; therefore, slope compensation is not needed. There are many studies in the literature about the AOT control solutions that have been published [15-21]. In Reference [17], the on-time AOT control is modulated by the output of the error amplifier rather than fixed voltage. However, the frequency of AOT control is still easily affected by the input voltage and load current changes.

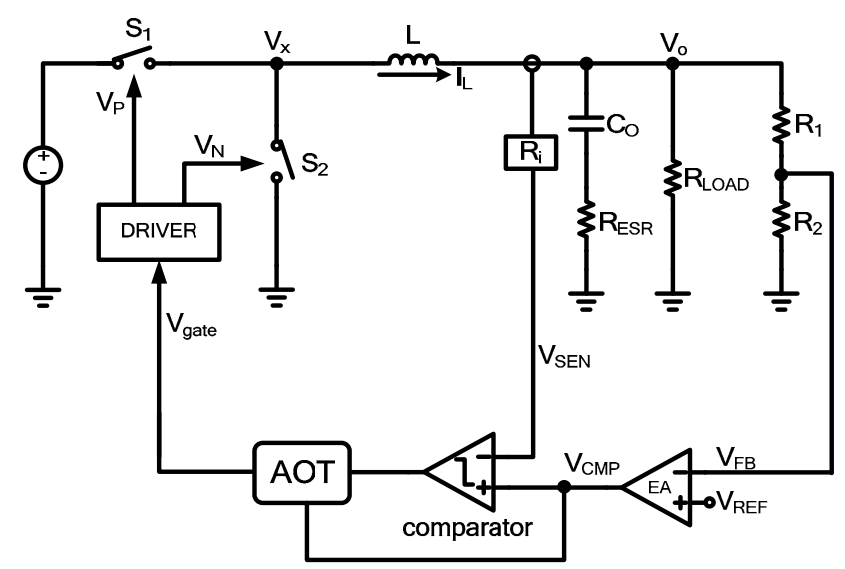

Figure 2. Conventional AOT control scheme.

No matter the AOT or COT scheme, as long as it is the current-mode control, the current sensor is usually required [22-25]. As can be seen from Figure 1b, the Ri represents 
the current sensor. At present, many current sensors have been proposed [4,12,15,26-33]. Among these current sensors, Hall-effect current sensors are very sensitive to the EMI of the converter [29]. However, the feature of the Hall sensor is to ensure that the power circuit and sensor can be electrically isolated. Aiello et al. [30] use a split-drain MOS transistor (MagFET) to realize an EMI-immune contactless current sensor. The low-cost isolation current sensors based on the giant magnetoresistance effect are proposed in [31,32]. Hall-effect current sensor with EMI immune is proposed in [33].

Typically, contactless current sensors are mainly used for current sensing and measuring in smart grids or in situations where electrical isolation is required [29-33]. Therefore, from the perspective of application and integration, the contactless current sensor solutions may not be suitable for low-power conversion IC.

Studies in the literature $[23,24]$ proposed a sensorless solution, which uses a predictive method to estimate inductor current. The sensing methods proposed in $[4,6,15,26-28,34]$ are summarized in what follows.

In Figure 3, the sensing method in [26,34] employed the resistor $R_{\text {sense }}$ in series with the inductor to measure $I_{L}$ by sensing resistive voltage. This sensing technique breaks the origin loop and inserts the sensing component. The disadvantage of this method is that the system power consumption will increase due to the resistor.

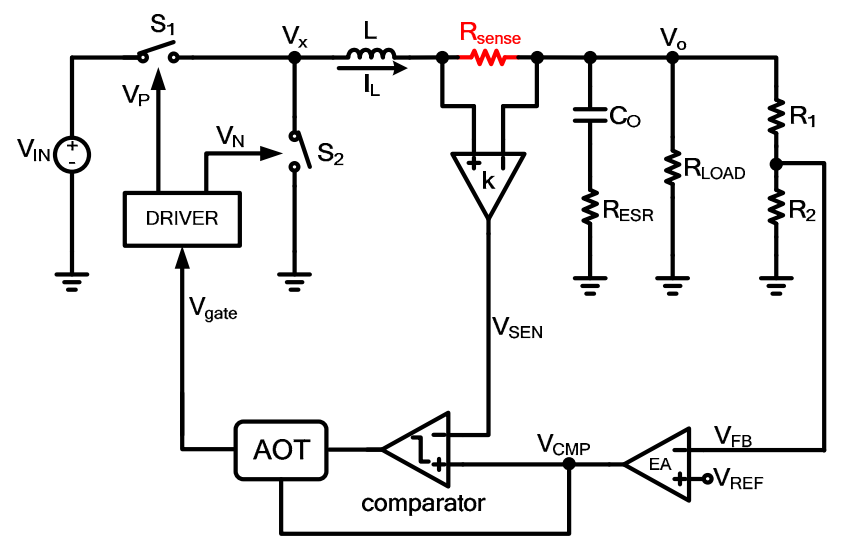

Figure 3. AOT scheme with the inductor current-sensing resistor.

Another current-sensing method, shown in Figure 4, is to parallel a set of low-pass filters (i.e., $\mathrm{R}_{\mathrm{S}}, \mathrm{C}_{\mathrm{S}}$ ) in the inductor $\mathrm{L}$. The disadvantage is that additional components, Rs and Cs, are needed at off-chip [15]. This sensing technique obtains the inductor current information without breaking the origin loop.

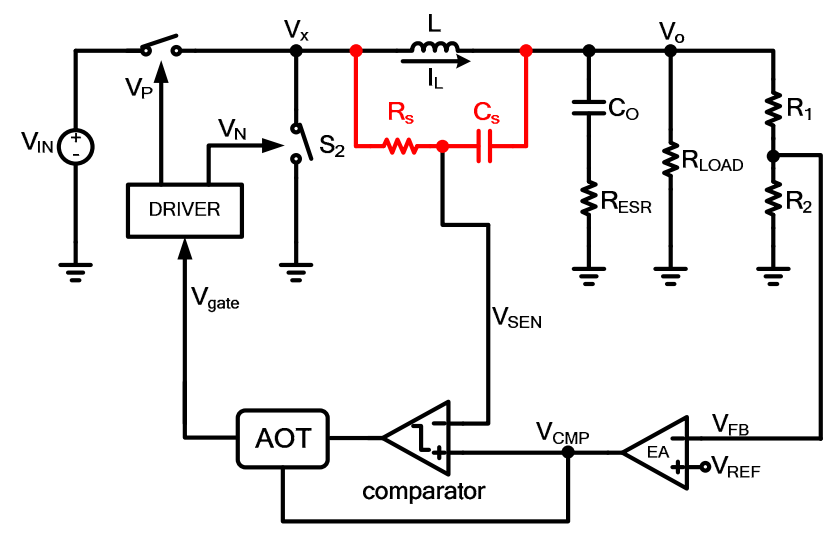

Figure 4. AOT scheme with the Rs, Cs sensing components.

In Figure 5, an active current-sensing (ACS) technique was proposed by Chen et al. to sense inductor current [27]. The ACS senses the voltage across the inductor and converts 
the current information into $\mathrm{V}_{\mathrm{SEN}}$. Therefore, the ACS also obtains the inductor current information without breaking the origin loop. Unfortunately, the switching voltage $V_{P}$, $V_{N}$ will cause the voltage $V_{X}$ to change between 0 and $V_{I N}$. Due to the large variation of voltage $V x$ and the off-chip sensing, the sensed $V_{\text {SEN }}$ would include some non-ideal effects.

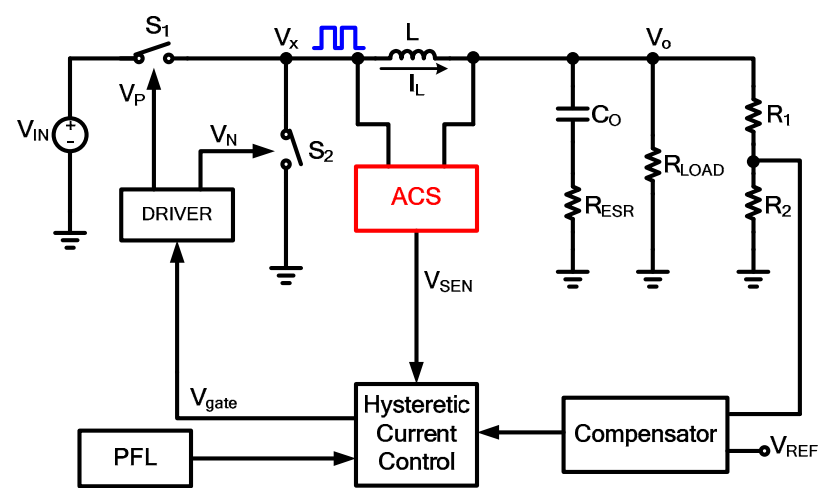

Figure 5. Hysteretic scheme with active current-sensing technique.

Similarly, Hwang et al. [6] proposed the optimum damping control in Figure 6 to improve the dynamic response. The sensing points are the same [27], and the voltage $V_{X}$ changes between 0 and $V_{\text {IN }}$. Additionally, this sensing technique is a no-break loop method.

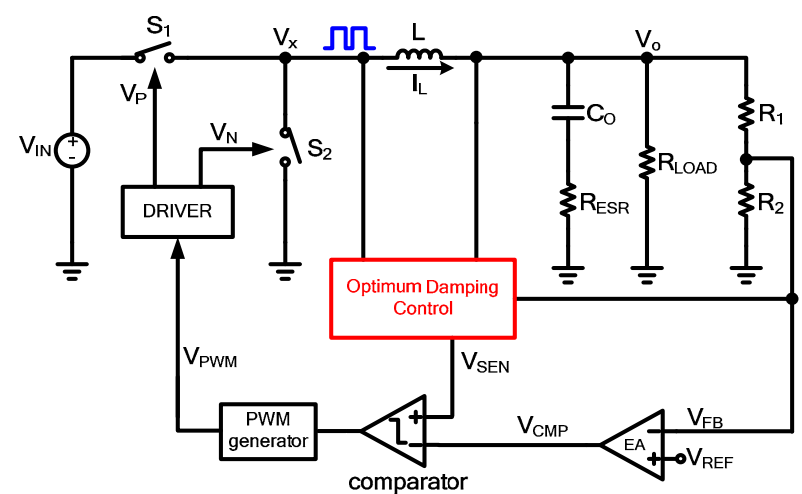

Figure 6. PWM control scheme with rail-to-rail current-sensing technique.

Chen et al. [28] proposed an active current-sensing technique for hysteresis-currentcontrolled (HCC) buck converter, as shown in Figure 7. However, the sample and hold circuits are required in this control scheme, and the ACS will generate sparks, which affect the transient response [4].

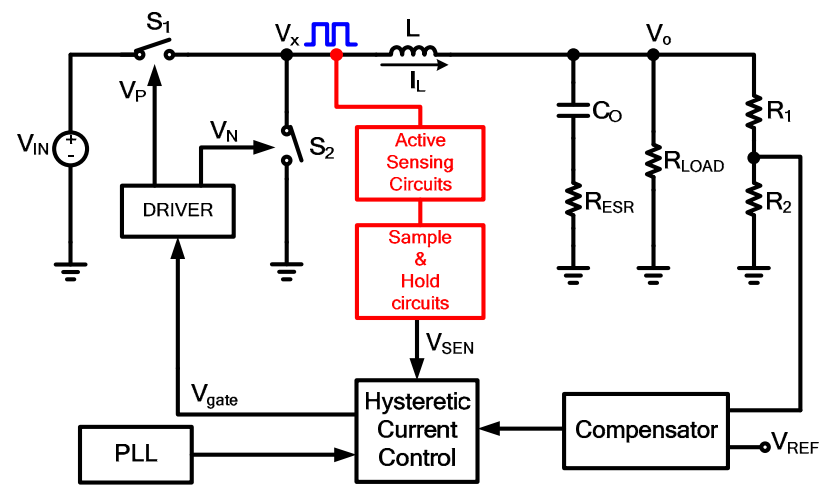

Figure 7. Active current-sensing constant-frequency HCC buck converter. 
This paper presents a novel inductor current sensing circuit. The proposed current sensor obtains the virtual inductor current by switching. The voltage of the proposed sensing point is more stable than the other methods in $[4,6,15,26-28,34]$. Moreover, the circuit is simple and can be integrated into existing control schemes such as AOT and COT. Since the sensor is integrated into the chip, the proposed control scheme provides a more stable control signal with less interference from the off-chip environment.

The paper is organized as follows: Section 2 describes conventional current mode COT / AOT control schemes. Section 3 presents the proposed scheme and implementation. Section 4 introduces the design procedure and modeling analysis with MathCAD. Section 5 shows the SIMPLIS simulation results. Finally, conclusions are given in Section 6.

\section{Conventional Control Scheme Descriptions}

\subsection{Current Mode COT (CM-COT) Operating Principle}

Figure $1 \mathrm{~b}$ shows the conventional current mode COT control scheme. The operation of Figure $1 b$ is described as follows: when the triangle wave $V_{S E N}$ is lower the voltage $V_{C M P}$, the comparator is high. Then, the block, named "Ton" in Figure 1b, produces a constant ON time, which turns on switch S1. The state of switches S1 and S2 are complementary and non-overlapping. This means the control scheme turns on S1 for a fixed ON time and then turns off until the $\mathrm{V}_{\mathrm{SEN}}$ drops to its limit voltage $\mathrm{V}_{\mathrm{CMP}}$, and then turns on $\mathrm{S} 1$ again. The block named "EA" means the error amplifier, which includes the trans-conductor and the compensation network. The main purpose of the EA is to regulate Vo and determine OFF time.

In contrast to the pulse width modulation (PWM) control schemes, this control scheme does not need additional slope compensation in the current loop to ensure stability. However, since the switching frequency is allowed to change, the switching control signal looks more jittery in valley current mode control.

Conceptually, in the current control mode, the inductor becomes a controlled current source due to the current loop. Therefore, the whole system becomes a first-order system instead of a second-order system. The phase lag caused by the poles of the power stage is reduced from 180 degrees to 90 degrees. Smaller phase delay makes the compensation of voltage sensing path much easier. The power supply is not so sensitive to variations in capacitance or inductance [35].

\subsection{Current Mode AOT (CM-AOT) Operating Principle}

The AOT control scheme in Figure 2 is derived from the COT structure. Therefore, the operation principle of the AOT scheme is roughly the same as the COT scheme. The main difference is that the $\mathrm{ON}$ time is controlled by the voltage $\mathrm{V}_{\mathrm{CMP}}$, rather than constant.

\section{Proposed Control Scheme and Implementation}

\subsection{Operating Principle}

Figure 8 shows the proposed control scheme, which is a current mode AOT control. The basic operating principle is the same as the AOT control scheme, described in Section 2.2. Different from $[4,6,15,26-28]$, a novel current sensing technique is proposed in this control scheme. In Figure 8, the proposed virtual inductor current (VIC) senses $V_{\text {IN }}$ and $V_{O}$ to generate $V_{S E N}$ instead of $V_{X}$ and $V_{O}$. Since $V_{I N}$ is more stable than $V_{X}$, the VIC sensing results are expected to be better than [27]. 


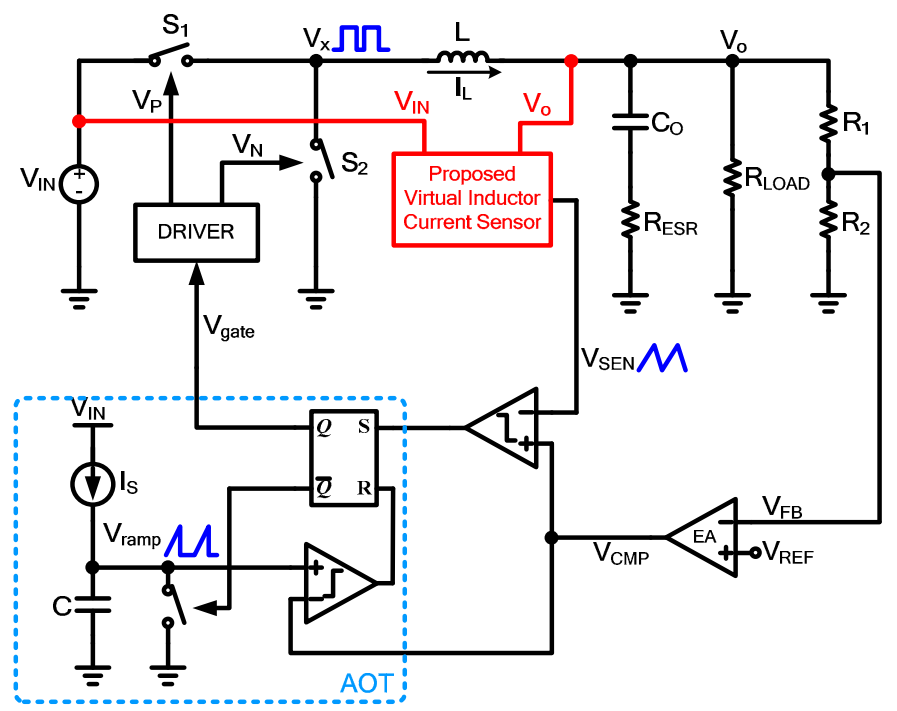

Figure 8. Proposed control scheme.

\subsection{Proposed Virtual Inductor Current Sensor}

The proposed VIC sensor is shown in Figure 9. As is commonly known, the voltage and current on the inductor can be expressed as Equation (1), where L is the inductance, $\mathrm{V}_{\mathrm{L}}$ and $\mathrm{I}_{\mathrm{L}}$ are the voltage and current on the inductor, respectively. From Equation (1), the current variation $\Delta \mathrm{I}_{\mathrm{L}}$ will be proportional to $\mathrm{V}_{\mathrm{L}}$. Figure 10 illustrates the relation of inductor current and voltage, where $S 1, V_{x}$, and $V_{o}$ are shown in Figure 8. Conceptually, $\mathrm{I}_{\mathrm{L}}$ waveform is similar to current charging/discharging a capacitor. Therefore, as long as $\mathrm{V}_{\mathrm{x}}, \mathrm{V}_{\mathrm{O}}$ can be included in the charging/discharging current, $\mathrm{I}_{\mathrm{L}}$ can be converted to $\mathrm{V}_{\mathrm{SEN}}$. However, this paper does not sense $V_{x}$ but senses $V_{\text {IN }}$ voltage. Nevertheless, it can also meet the requirements through S3 in Figure 9.

$$
\Delta I_{L}=\frac{V_{L}}{L} \cdot \Delta t
$$

In Figure $9, \mathrm{~V}_{\mathrm{IN}}, \mathrm{V}_{\mathrm{O}}, \mathrm{V}_{\mathrm{P}}, \mathrm{V}_{\mathrm{SEN}}$ are defined as terminals and represented by $\mathrm{I} / \mathrm{O}$ pin symbols. In order to clearly present the implementation of the VIC sensor, the VIC sensor is combined into the proposed control scheme and shown in Figure 11.

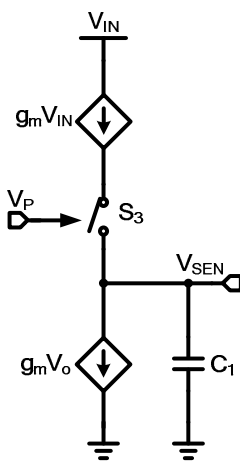

(a) Conception

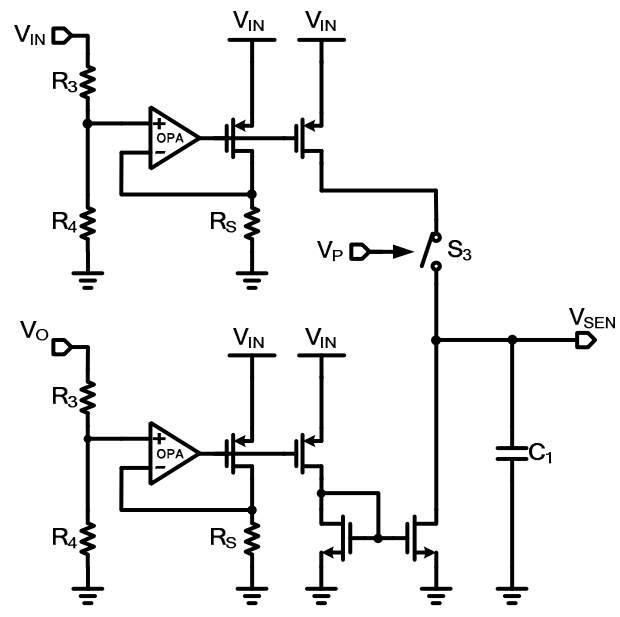

(b) Circuit implementation

Figure 9. Proposed virtual inductor current sensor. 


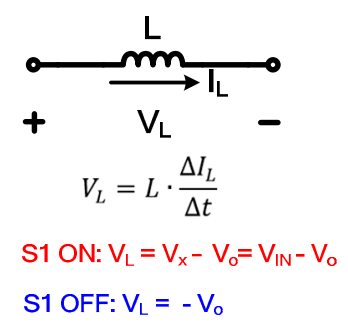

(a) voltage/current of inductor

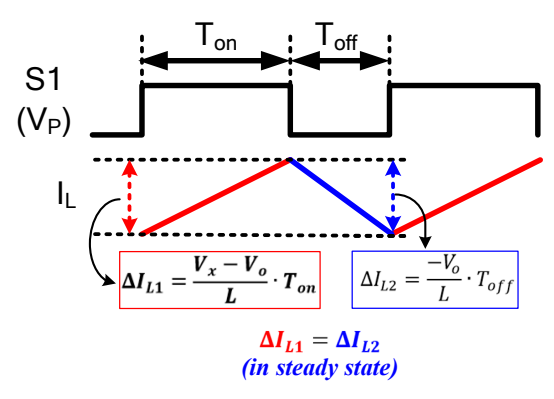

(b) current waveform on inductor

Figure 10. Voltage current relationship of inductor.

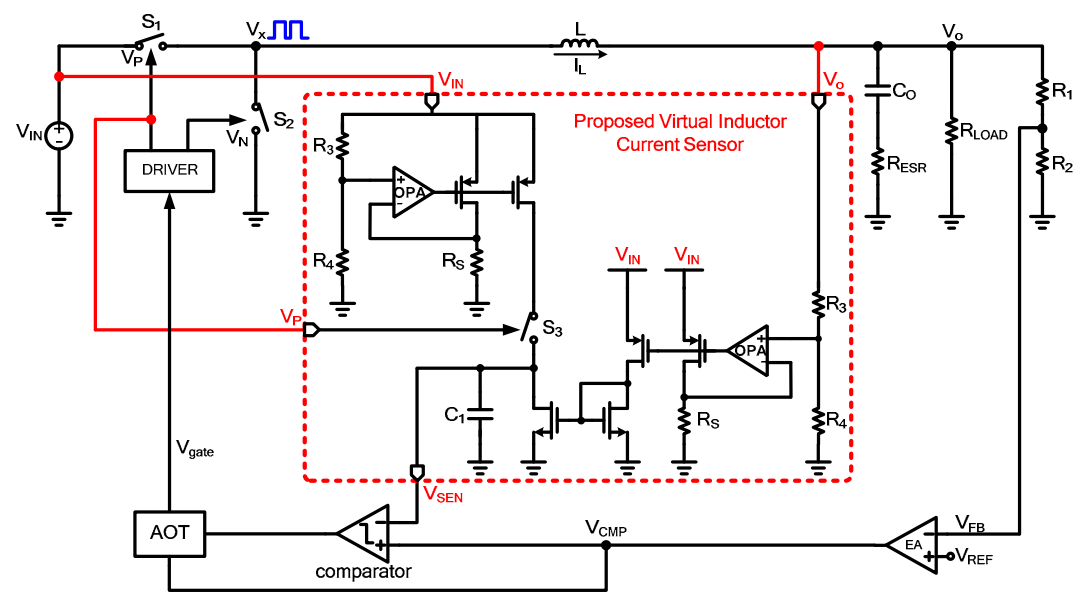

Figure 11. Proposed VIC sensor in control scheme.

\section{Design Procedure}

\subsection{Buck Converter Modeling}

To analyze the stability of the system, we need to obtain the closed-loop transfer function and understand the position of zeros and poles and their influence on the system. The open-loop modeling method for current-mode control is described in [36-38]. In fact, it is not easy to develop an accurate small-signal model of current-mode converters. At present, the current-mode converter model proposed by Ridley is the most common small-signal model [39]. In recent years, a more effective and intuitive circuit model for current-mode controls was also proposed by Li et al. [40].

In Figure 12, the modulator $G_{p}(s)$ consists of the comparator, the inductor, the switches, and the on-time block. In the modeling process, all of them are modeled as a single entity rather than breaking them into parts. By the modeling method described in [39], the transfer function from the signal $V_{C M P}$ to the output signal $V_{O}$ can be presented as Equation (2).

$$
G_{P}(s)=\frac{v_{o}(s)}{v_{C M P}(s)} \approx \frac{1}{R_{i}} \cdot \frac{1}{1+\frac{s}{Q \cdot \omega}+\frac{s^{2}}{\omega^{2}}} \cdot \frac{R_{L O A D}\left(R_{E S R} C_{o} s+1\right)}{\left(R_{L O A D}+R_{E S R}\right) C_{o} s+1}
$$

where $R_{i}$ is the current sensing gain, $\omega=\frac{\pi}{T_{o n}}$ and $Q=\frac{2}{\pi}$. It is evident from Equation (2) that a double-pole condition may lead to system instability. 


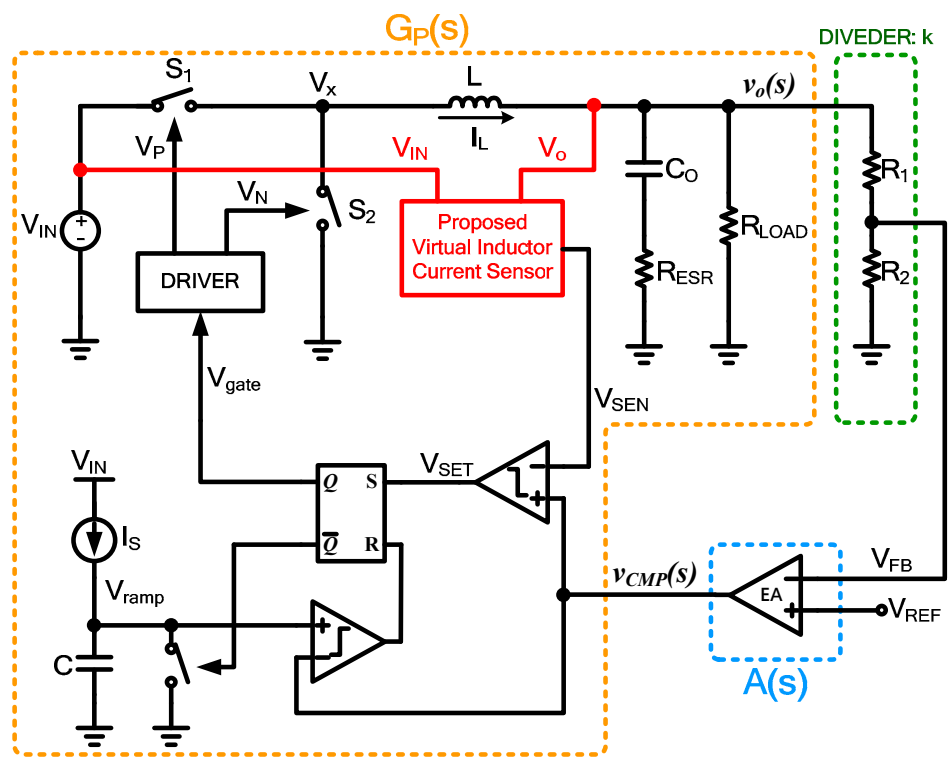

Figure 12. CM-AOT modeling.

\subsection{Crossover Frequency $f_{C}$ Determination}

Higher bandwidth will have a fast transient response. However, the bandwidth increase will sacrifice the circuit stability, which makes the circuit more susceptible to switching noise. Therefore, how to balance the stability margin and transient response is very important. In fact, due to the current sampling effect, the current-mode control also introduces double poles at $1 / 2 f_{s w}$ [39]. Therefore, for sufficient phase margin, we will often design the crossover frequency at $1 / 10-1 / 6$ of the switching frequency $f_{\text {sw }}$, as shown in Equation (3).

$$
f_{c} \leq\left(\frac{1}{10} \sim \frac{1}{6}\right) \cdot f_{S W}
$$

\subsection{Compensator Design}

$\mathrm{A}(\mathrm{s})$ is the most critical for loop compensation design, which determines the crossfrequency, DC gain, phase, and gain margin of the voltage loop. To describe the loop gain, Figure 12 is simplified to Figure 13. In Figure 13, the converter loop gain T(s) can be expressed in Equation (4). In this paper, a type II compensation network is used at the output end of the operational amplifier, which is composed of resistance $R_{t}$, and capacitance $C_{t}$ and $C_{p}$ in parallel. The compensation network combined with an operational amplifier can be expressed as the compensator gain $\mathrm{A}(\mathrm{s})$, as shown in Figure 14. The transfer function $\mathrm{A}(\mathrm{s})$ is given by Equation (5). In the compensator design procedure, the zero $w_{z}$ is set to cancel the output pole of the peak current-mode buck topology, expressed as Equation (6). The compensation pole $w_{p 2}$ is set at the lower frequency between the output capacitor ESR zero and $1 / 2$ of the operating frequency. $w_{p 1}$ is extrapolated to make the feedback system more stable.

$$
\begin{gathered}
\mathrm{T}(\mathrm{s})=G_{P}(s) \cdot A(s) \cdot k \\
\mathrm{~A}(\mathrm{~s})=\frac{v_{C M P}(s)}{v_{F B}(s)}=g_{m} \cdot R_{t h o} \cdot \frac{\left(1+\frac{s}{w_{z}}\right)}{\left(1+\frac{s}{w_{p 1}}\right) \cdot\left(1+\frac{s}{w_{p 2}}\right)}
\end{gathered}
$$

where $w_{z}=\frac{1}{R_{t} \cdot C_{t}}, w_{p 1}=\frac{1}{R_{t h} \cdot C_{t}}, w_{p 2}=\frac{1}{R_{t} \cdot C_{p}}$

Set the $w_{z}$ of the compensator to cancel the output pole as follows:

$$
w_{z}=\frac{1}{R_{L O A D} \cdot C_{o u t}}, \quad f_{z}=\frac{w_{z}}{2 \pi}
$$


Set the $w_{p 2}$ of the compensator at about $1 / 2$ of the switching frequency, as shown in Equation (7).

$$
w_{p 2} \approx \frac{1}{2} \cdot w_{s}=\frac{1}{2} \cdot\left(2 \pi f_{s w}\right)
$$

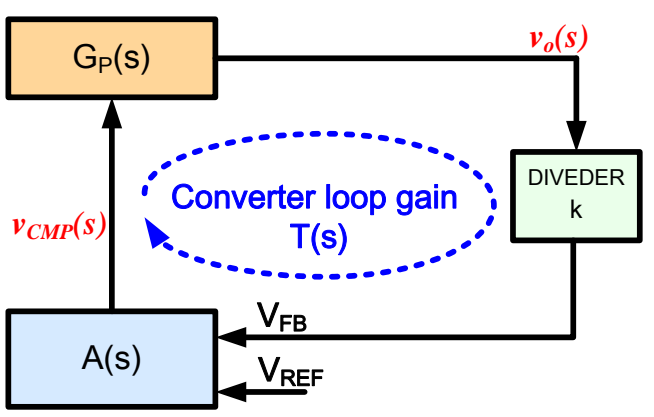

Figure 13. Block diagram for feedback loop.
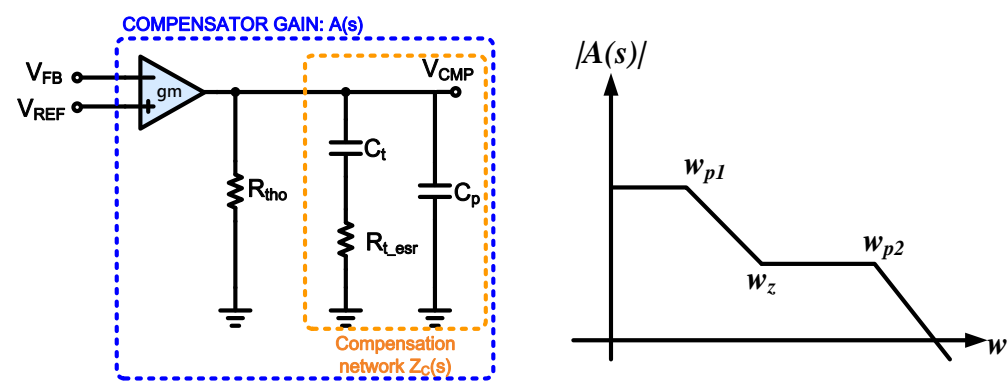

Figure 14. Compensator gain.

\subsection{Stability Analysis}

Step1: Substitute Table 1 value into Equation (2), then enter the equation into MathCAD and the Bode plot of the $G_{p}(s)$ can be drawn in Figure 15, where set $R_{i}=2, T_{\text {on }}=0.7 \mu \mathrm{s}$. In Figure $15, w_{\text {pout }} \approx \frac{1}{R_{L O A D} \cdot C_{0}}$ i.e., $f_{\text {pout }}=4.4 \mathrm{kHz}$.

Table 1. Simulation condition.

\begin{tabular}{ccc}
\hline Component & Value & Unit \\
\hline $\mathrm{R}_{\mathrm{LOAD}}$ & 3.6 & $\Omega$ \\
$\mathrm{C}_{\mathrm{O}}$ & 10 & $\mu \mathrm{F}$ \\
$\mathrm{L}$ & 4.7 & $\mu \mathrm{H}$ \\
$\mathrm{R}_{\mathrm{ESR}}$ & 5 & $\mathrm{~m} \Omega$ \\
\hline
\end{tabular}

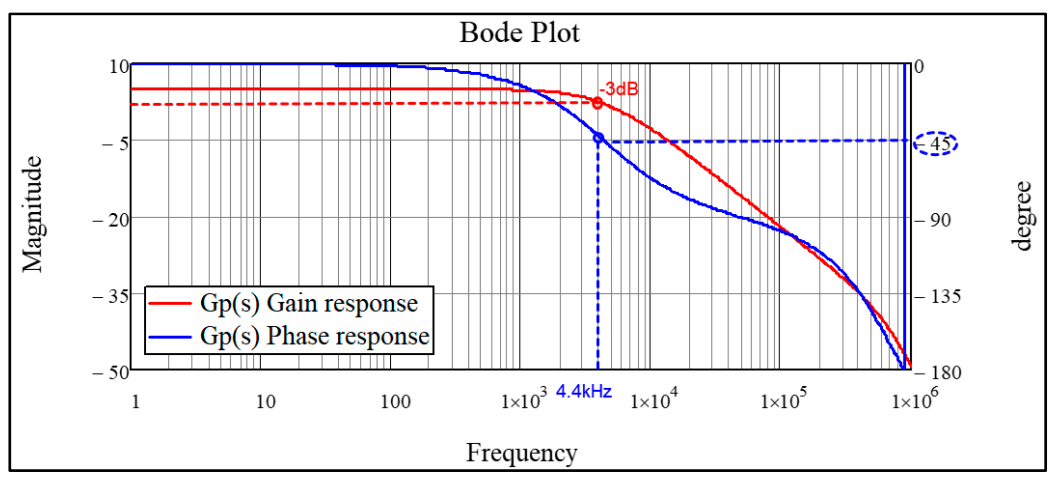

Figure 15. Bode plot of $G_{p}(s)$ for buck converter. 
Step2: As expressed in Equation (6), set the zero of the compensator $f_{z}=f_{\text {pout }}=4.4 \mathrm{kHz}$. From (7), set $f_{p 2} \approx 3 \mathrm{MHz}$. By Equation (5), suppose $C_{t}=200 \mathrm{pF}$, then $R_{t}=180 \mathrm{k} \Omega$, $C_{p}=200 \mathrm{fF}$ can be obtained. The compensator gain is set at $60 \mathrm{~dB}$, which can be adjusted according to the entire loop response. Suppose $R_{\text {tho }}=1 \mathrm{M} \Omega$, then $g_{\mathrm{m}}=1 \mathrm{~mA} / \mathrm{V}$, and $f_{p 1} \approx 800 \mathrm{~Hz}$. Finally, substitute all the above numbers into Equation (5), then enter the equation into MathCAD, and the Bode plot of the compensator is drawn in Figures 16 and 17.

Step3: Enter Equation (4) into MathCAD and substitute $k$ with 0.5. The Bode plot of the loop response $\mathrm{T}(\mathrm{s})$ is drawn in Figures 16 and 17. It can be seen that the $\mathrm{T}(\mathrm{s})$ phase margin is about 25 degrees, $\mathrm{DC}$ gain is about $61 \mathrm{~dB}$, and the crossover frequency $f_{c}$ is about $500 \mathrm{kHz}$.

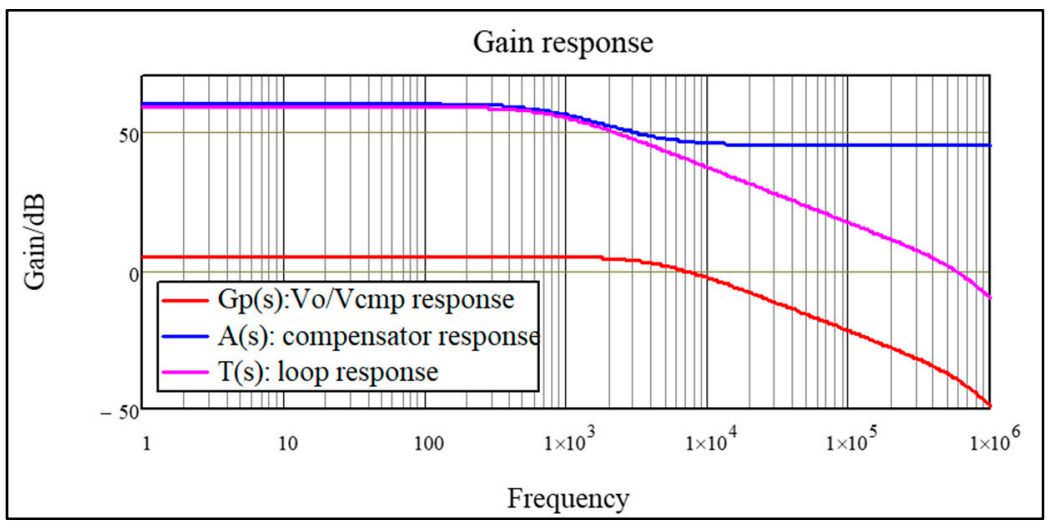

Figure 16. Gain response of $G_{p}(s), A(s)$, and $T(s)$.

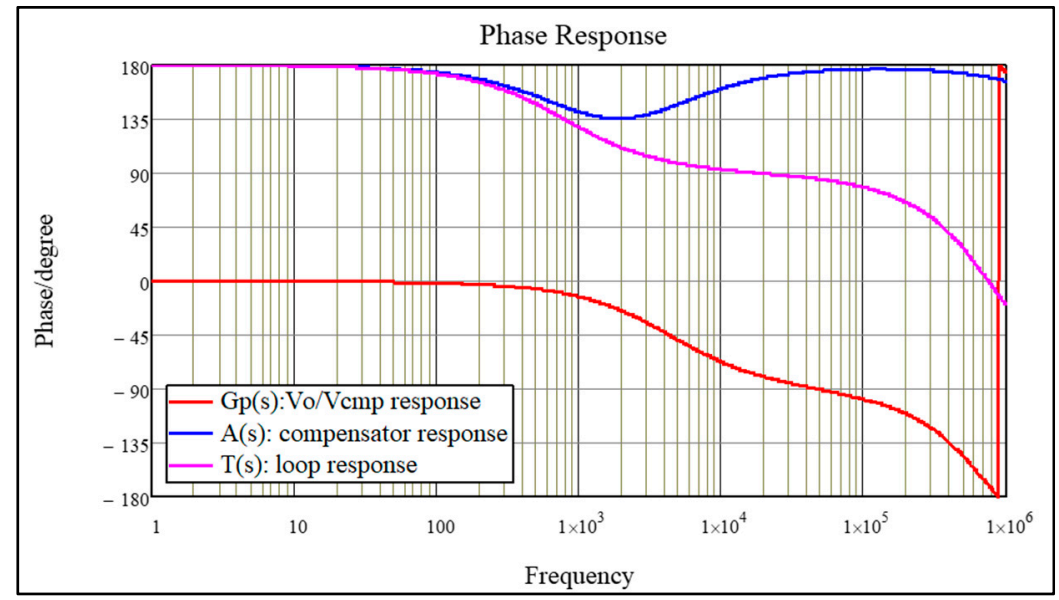

Figure 17. Phase response of $G_{p}(s), A(s)$, and $T(s)$.

\section{Simulation Results}

\subsection{CM-AOT SIMPLIS Schematic Building}

In this section, the SIMPLIS tool was used to simulate the proposed CM-AOT scheme. The SIMPLIS schematic is displayed in Figure 18. 


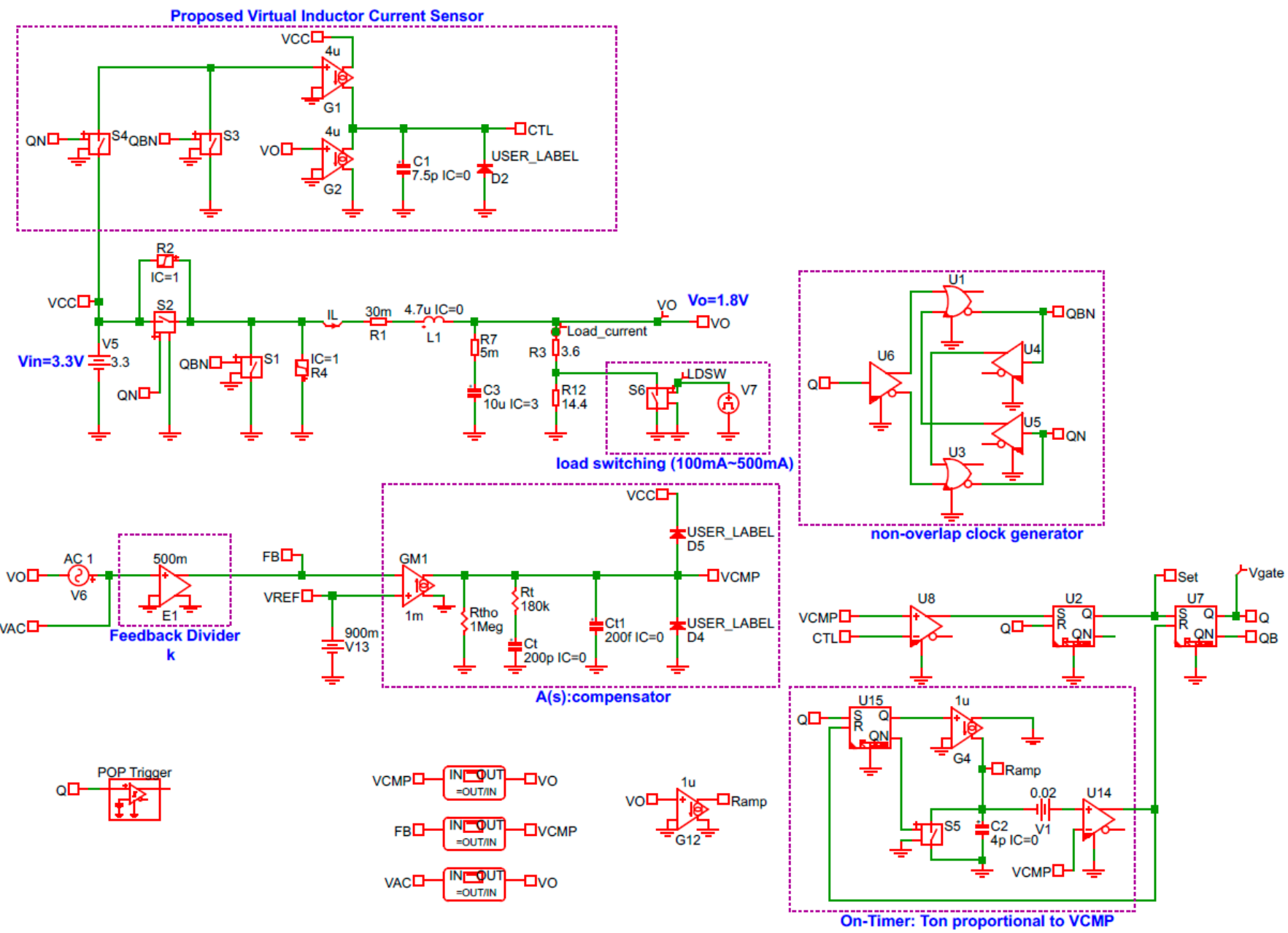

Figure 18. The SIMPLIS simulation schematic.

\subsection{Schematic Stability Analysis}

The stability analysis of the proposed scheme was simulated by the SIMPLIS tool, and the results are shown in Figure 19, in which legend label names follow the previous section definition. It can be seen from Figure 19 that the crossover frequency of loop response is about $523 \mathrm{kHz}$, the phase margin is about 46 degrees, and the DC gain is about $62 \mathrm{~dB}$.

In the previous section, we used MathCAD to draw the Bode plot of the transfer function by numerical approach. However, in this section, we used SIMPLIS to build the circuit architecture and confirm the stability with the Bode plot. In order to find the difference between them, the waveforms in Figures 16, 17 and 19 are redrawn in Figures 20 and 21. From Figures 20 and 21, we found that the results of MathCAD and SIMPLIS have some differences. There are two possible reasons for these differences: 1 . Equation (2) has been simplified; 2 . the proposed VIC cannot be replaced only by the current gain Ri in Equation (2). Nevertheless, Equation (2) is very close to the real behavior of the system.

From the perspective of stability, A(s) almost determines whether the system is stable or not. As the switching converter contains analog parts and digital parts, the AC stability analysis is not easy. In many cases, non-convergence may occur in AC simulation. To solve the non-convergence issue, the most common method is to run the transient simulation first, then replace the DC point in AC simulation with the DC operation point from transient simulation. At present, many computer-aided design (CAD) software programs, such as LTspice, LTpowerCAD, can help the designers to design the compensator for stability issues. In general, the crossover frequency is higher, and the phase margin is worse. The designer can reduce the loop gain to obtain a good phase margin. However, the loop gain 
reduction would sacrifice the DC regulation accuracy. The rule of thumb is to recommend the loop gain of $60 \mathrm{~dB}$.

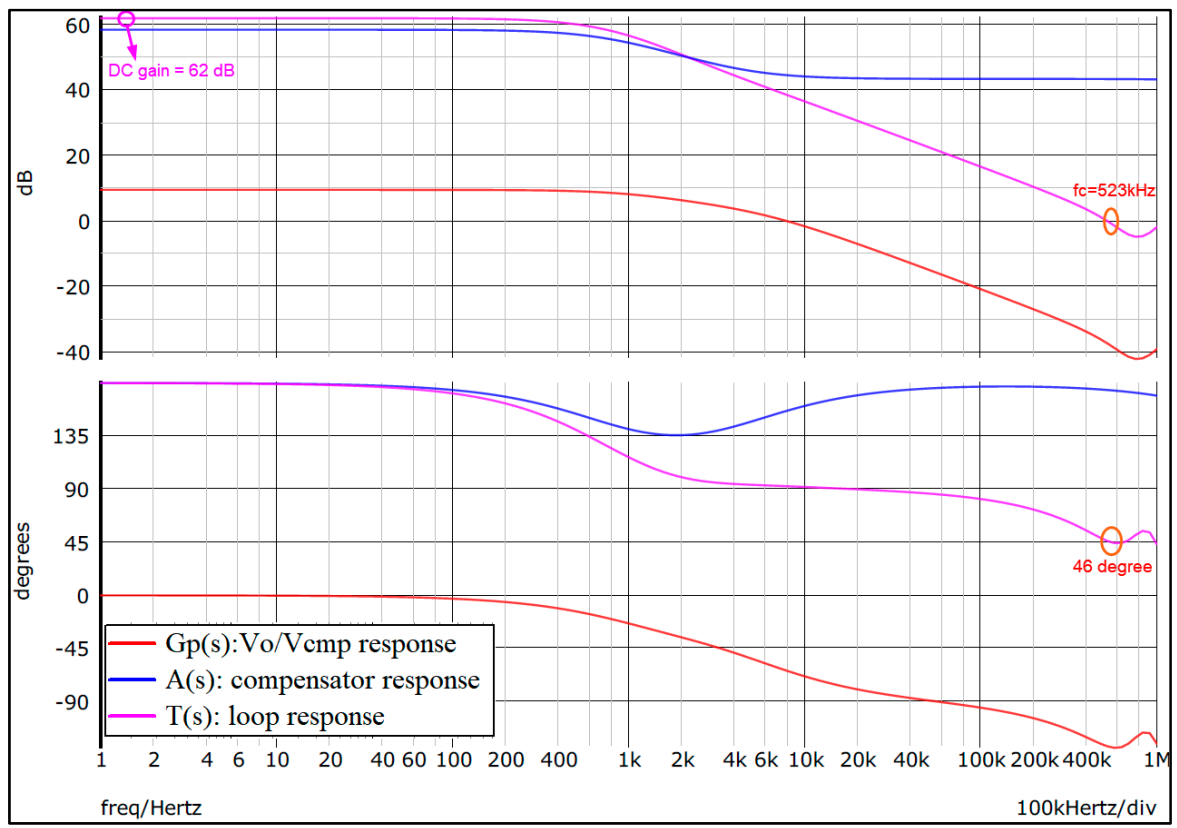

Figure 19. Bode plot results with SIMPLIS.

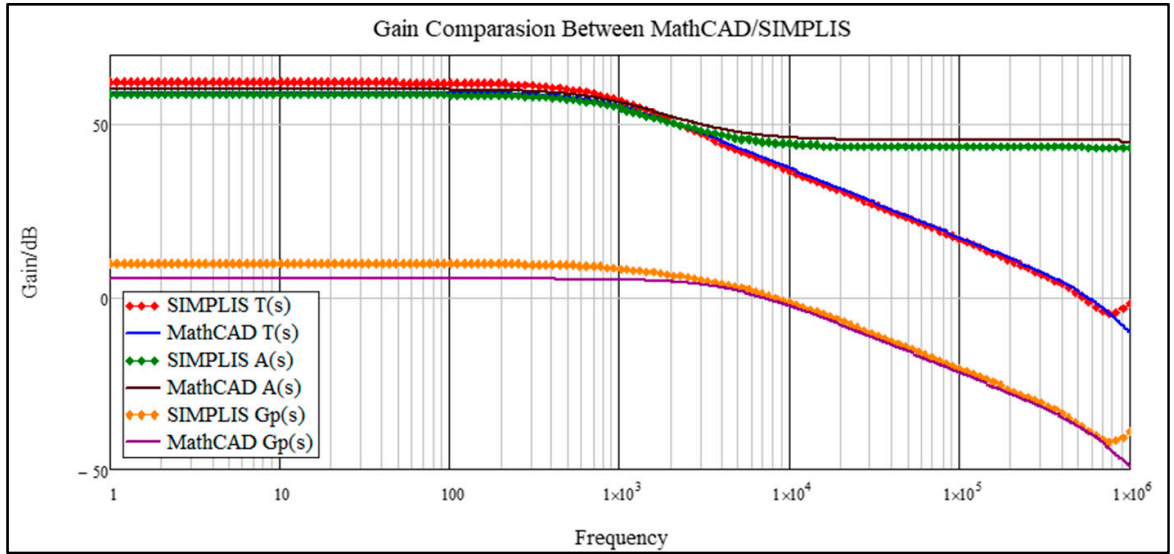

Figure 20. Gain comparison between MathCAD and SIMPLIS.

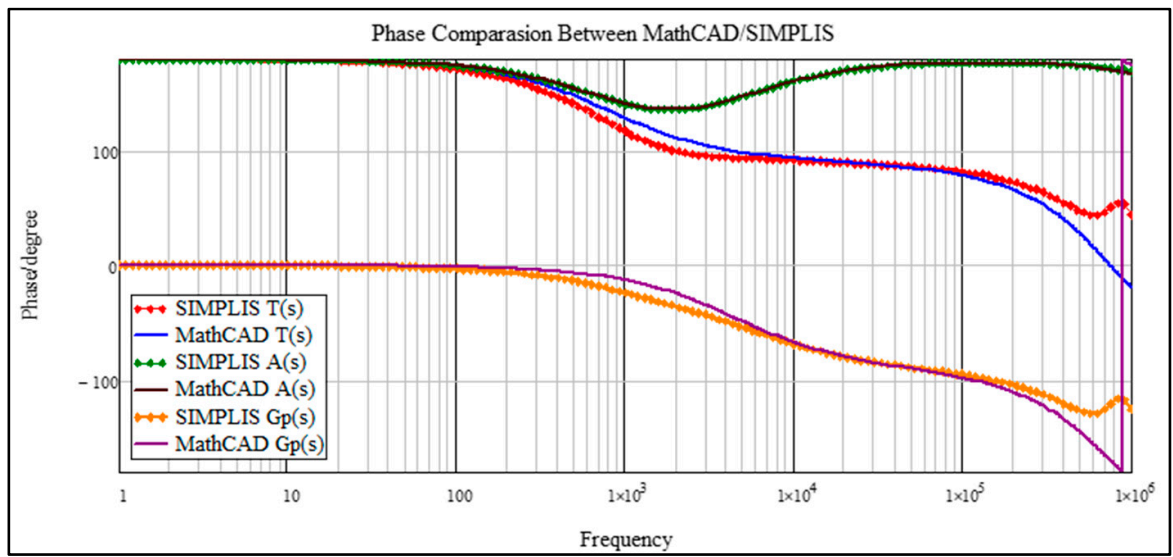

Figure 21. Phase comparison between MathCAD and SIMPLIS. 
It should be noted that the type selection of compensation network depends on the control mode. In general, the voltage-mode control scheme needs to adopt the type III compensation network, which is fairly complicated. Fortunately, the current-mode control scheme only requires the type II compensation network. Thus, the stability issue would be relieved.

\subsection{Transient Performance}

Figure 22 shows the load transient waveforms. For the step-up and step-down load current steps between $0.1 \mathrm{~A}$ and $0.5 \mathrm{~A}$, the output recovers to within $1 \%$ of the expected level $1.8 \mathrm{~V}$ in $1.98 \mu \mathrm{s}$ and $1.6 \mu \mathrm{s}$, respectively. In addition, the overshoot and undershoot voltages can also be controlled within $26 \mathrm{mV}$.

Under 0.5 A load current, the acceptable input range of the proposed converter is 3.0-3.6 V , and the voltage output range is 1.0-2.5 V. The input/output characteristics are shown in Figure 23. Figure 23 shows that the maximum ripple voltage of the converter is $2.5 \mathrm{mV}$ when $\mathrm{Vin}=3.6 \mathrm{~V}$ and $\mathrm{Vo}=2.5 \mathrm{~V}$.

To ensure system reliability, the transient performance of the proposed converter was simulated with the variations of passive/active devices. First, the inductor was simulated with $\pm 5 \%$ of variations. The results showed the recovery time would vary from $1.5 \mu$ s to $2.0 \mu \mathrm{s}$ with $4.465 \mu \mathrm{H}$ to $4.935 \mu \mathrm{H}$ of the inductance, respectively. Secondly, the recovery time changed from $1.87 \mu$ s to $1.3 \mu$ s with the gm of the operational amplifier from $0.9 \mathrm{~mA} / \mathrm{V}$ to $1.1 \mathrm{~mA} / \mathrm{V}$, respectively. Thirdly, the time would vary from $1.5 \mu$ s to $1.7 \mu$ s with $-10 \%$ to $+10 \%$ variations of DC gain. These simulation results show that the proposed system is insensitive to the device variations. Therefore, the reliability of the system is expected.

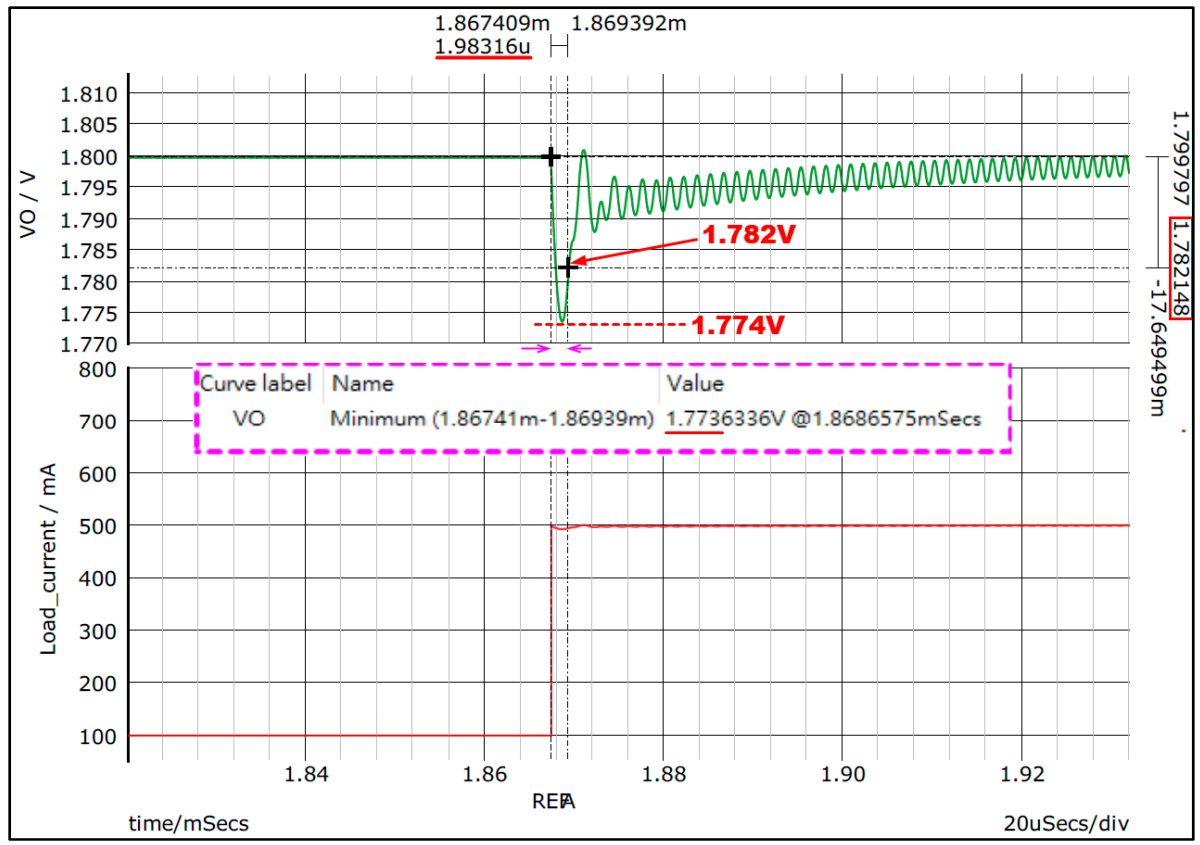

(a)

Figure 22. Cont. 


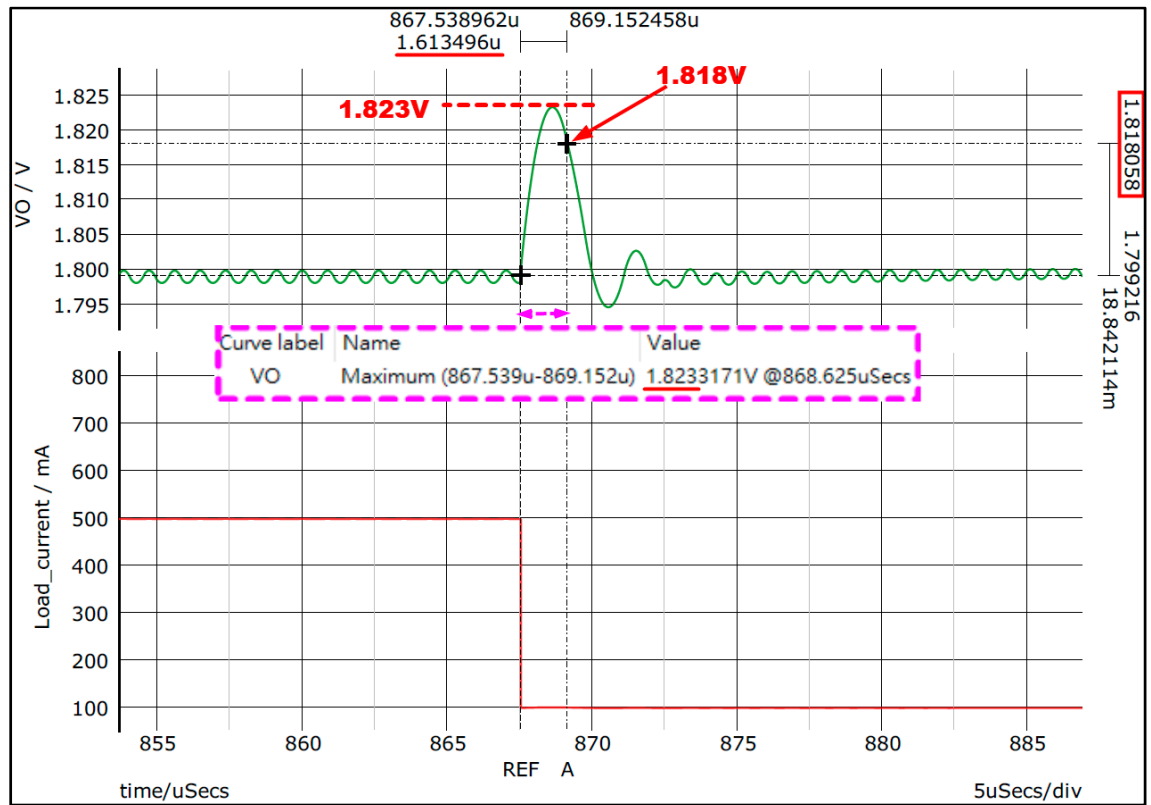

(b)

Figure 22. (a) Load current step-up behavior; (b) Load current step-down behavior.

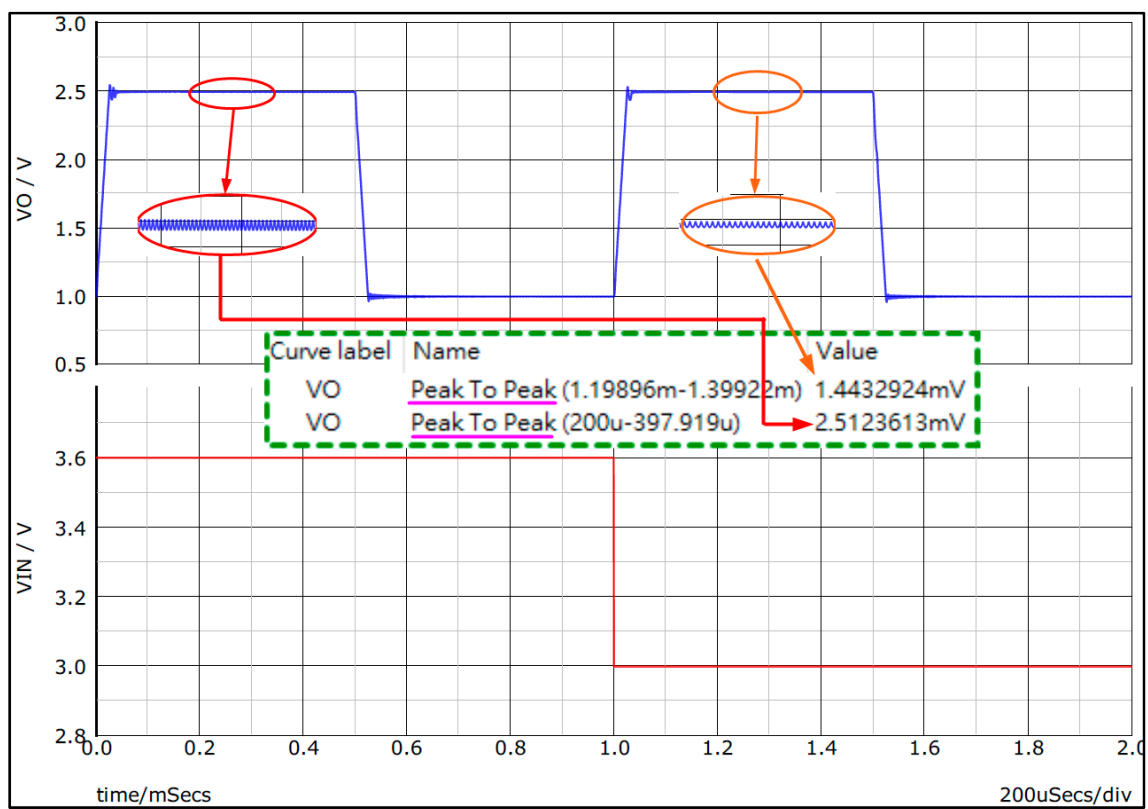

Figure 23. Input/output characteristics.

\subsection{Load Regulation/Line Regulation}

Load regulation is to measure the performance of a power supply. It is the capability to maintain a constant voltage (or current) level on the output despite changes in the load. We expect that a load change causes a small change in output, usually from $3 \%$ to $5 \%$. In this paper, under the condition of $1.8 \mathrm{~V}$ output voltage with the load current switching from $0.5 \mathrm{~A}$ to $0.1 \mathrm{~A}$, the load regulation was calculated by Equation (8). The simulation waveform is shown in Figure 24, and the calculation result is $-0.05 \%$.

$$
\text { Load Regulation }=\frac{\Delta V_{o}}{V_{o @ I L=0.5 A}} \cdot 100 \%
$$




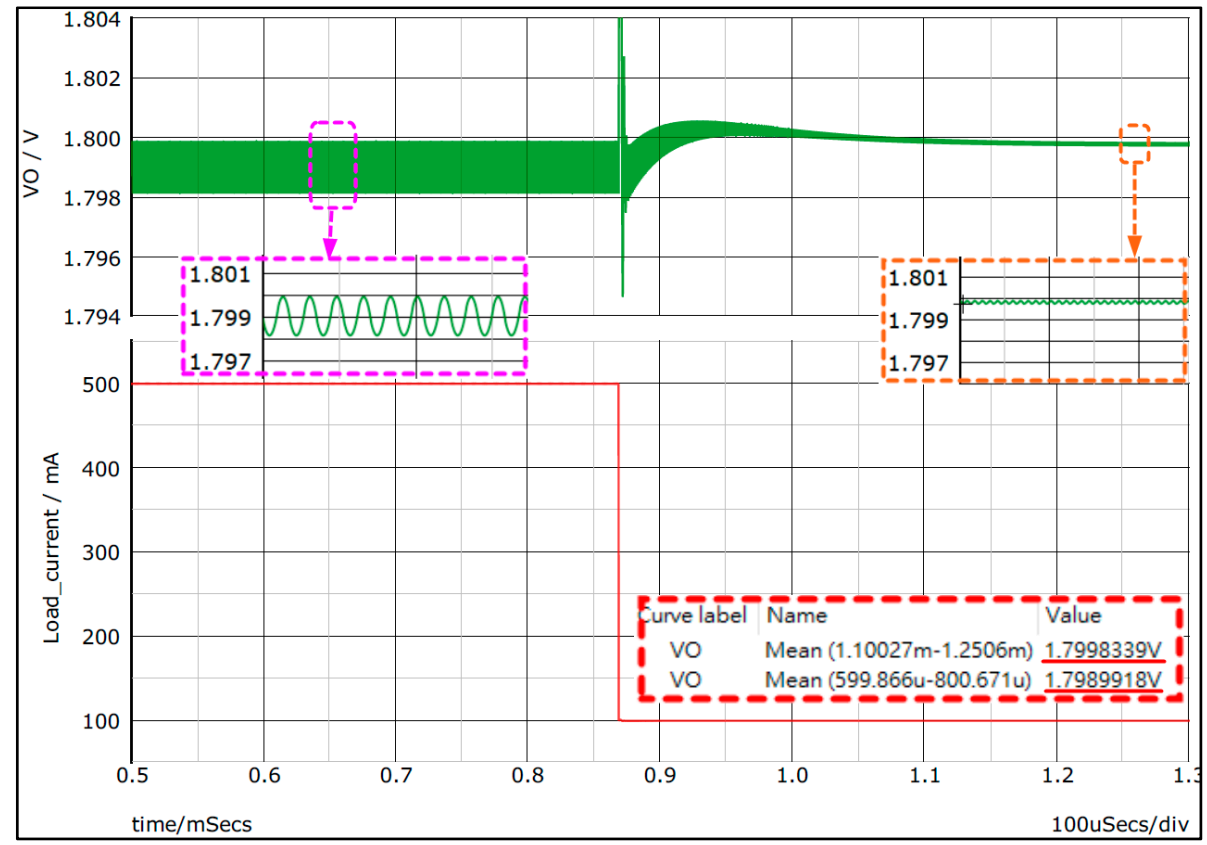

Figure 24. Waveform of load regulation.

Line regulation is the ability of a power supply to maintain a constant output voltage despite changes to the input voltage, as shown in Equation (9). The calculation result is close to 0 . As this is a system-level simulation, the simulation results of line regulation are meaningless and cannot reflect the real conditions.

$$
\text { Line Regulation }=\frac{\Delta V_{o}}{\Delta V_{\text {in }}} \cdot 100 \%
$$

\subsection{Performance List}

Table 2 presents the performance of the current-mode adaptive on-time control buck converter. The input voltage range is $3.0-3.6 \mathrm{~V}$. When the output voltage is $1.8 \mathrm{~V}$, and the load current steps between $100 \mathrm{~mA}$ and $500 \mathrm{~mA}$, the recovery time is smaller than $2 \mu \mathrm{s}$. The performance comparisons with reported converters are listed in Table 3.

Table 2. Performance summary.

\begin{tabular}{|c|c|c|}
\hline \multicolumn{2}{|c|}{ Input voltage } & $3.0-3.6 \mathrm{~V}$ \\
\hline \multicolumn{2}{|c|}{ Output voltage } & $1.0-2.5 \mathrm{~V}$ \\
\hline \multicolumn{2}{|c|}{$\begin{array}{c}\text { Max. output ripple } \\
(@ \text { Vin }=3.6 \mathrm{~V}, \mathrm{Vo}=2.5 \mathrm{~V})\end{array}$} & $2.51 \mathrm{mV}$ \\
\hline \multicolumn{2}{|c|}{ Max. load current } & $0.5 \mathrm{~A}$ \\
\hline \multicolumn{2}{|c|}{ Inductor/DCR * } & $4.7 \mu \mathrm{H} / 30 \mathrm{~m} \Omega$ \\
\hline \multicolumn{2}{|c|}{ Output capacitor/ESR } & $10 \mu \mathrm{F} / 5 \mathrm{~m} \Omega$ \\
\hline \multirow{2}{*}{$\begin{array}{l}\text { Transient response } \\
\qquad \mathrm{V}_{\mathrm{O}}=1.8 \mathrm{~V}\end{array}$} & $100 \mathrm{~mA}$ to $500 \mathrm{~mA}$ & $1.98 \mu \mathrm{s}$ \\
\hline & $500 \mathrm{~mA}$ to $100 \mathrm{~mA}$ & $1.6 \mu \mathrm{s}$ \\
\hline \multirow{2}{*}{$\begin{array}{l}\text { Transient voltage } \\
\qquad \mathrm{V}_{\mathrm{o}}=1.8 \mathrm{~V}\end{array}$} & Overshoot & $23 \mathrm{mV}$ \\
\hline & Undershoot & $26 \mathrm{mV}$ \\
\hline
\end{tabular}

${ }^{*}$ DCR: the DC resistance of inductor. 
Table 3. Performance comparisons with reported converters.

\begin{tabular}{lcccc}
\hline \multicolumn{1}{c}{ References } & 2018 [15] & 2020 [41] & 2021 [27] & This work \\
\hline Results & simulation & simulation & measurement & simulation \\
Control scheme & AOT & AOT & Hysteretic PLL & AOT \\
Process $(\mu \mathrm{m})$ & 0.35 & 0.18 & 0.35 & $0.35^{* *}$ \\
Input voltage $(\mathrm{V})$ & 12 & $3.3-5.0$ & $3.3-3.6$ & $3.0-3.6$ \\
Output voltage $(\mathrm{V})$ & 1.2 & 1.8 & $0.9-2.5$ & $1.0-2.5$ \\
Inductor $(\mu \mathrm{H})$ & 1 & 1.5 & 4.7 & 4.7 \\
Output capacitor $(\mu \mathrm{F})$ & 47 & 20 & 10 & 10 \\
Max. load current $(\mathrm{mA})$ & 5000 & 2000 & 600 & 500 \\
Load current step $(\mathrm{mA})$ & 4000 & 800 & 400 & 400 \\
Undershoot/overshoot $(\mathrm{mV})$ & $20 / 26$ & $13 / 14$ & $30 / 60$ & $23 / 26$ \\
Recovery time $(\mu \mathrm{s})($ rise/fall) & $<3$ & $6 / 2$ & $2.6 / 2.2$ & $1.98 / 1.6$ \\
\hline
\end{tabular}

** This work is a system-level simulation with SIMPLIS.

\section{Conclusions}

In this study, an adaptive on-time control buck converter with a novel virtual inductor current circuit was proposed. The modeling approach was derived and sketched by MathCAD and SIMPLIS. This paper describes the design parameters and design procedure in detail. Moreover, a system-level circuit topology was build and verified by SIMPLIS. This study proposed the implementation of the VIC circuit that is compatible with the existing AOT architecture. The sensing point of VIC is more stable than that of ACS in [27]. Hence, the overall performance would be better than [27]. The proposed buck converter can be implemented with TSMC $0.35 \mu \mathrm{m} 2 \mathrm{P} 4 \mathrm{M}$ CMOS processes further.

Author Contributions: H.-H.C., conceptualized and designed the prototype, simulated the whole system, wrote original draft preparation; H.-L.C. performed the verification and revised the paper; Y.-H.F. analyzed the data; S.-F.W. wrote the paper. All authors have read and agreed to the published version of the manuscript.

Funding: This research was funded by Ministry of Science and Technology, Taiwan, under Grants MOST 110-2222-E-346-001.

Conflicts of Interest: The authors declare no conflict of interest.

\section{References}

1. Chen, J.J.; Yang, F.C.; Chen, C.C. A new monolithic fast-response buck converter using spike-reduction current-sensing circuits. IEEE Trans. Ind. Electron. 2008, 55, 1101-1111. [CrossRef]

2. Chen, J.J.; Hwang, Y.S.; Hwang, B.H.; Jhang, Y.C.; Ku, Y.T. A dual-mode fast-transient average-current-mode buck converter without slope-compensation. In Proceedings of the 2018 7th International Symposium on Next Generation Electronics(ISNE) Conference, Taipei, Taiwan, 7-9 May 2018.

3. Huang, Q.; Zhan, C.; Burm, J. A 30-MHz Voltage-Mode Buck Converter Using Delay-Line-Based PWM Control. IEEE Trans. Circuits Syst. II 2018, 65, 1659-1663. [CrossRef]

4. Chen, J.J.; Hwang, Y.S.; Chen, J.H.; Ku, Y.T.; Yu, C.C. A New Fast-Response Current-Mode Buck Converter with Improved I2-Controlled Techniques. IEEE Trans. Very Large Scale Integr. (VLSI) Syst. 2018, 26, 903-911. [CrossRef]

5. Chen, J.J.; Hwang, Y.S.; Lin, J.Y.; Ku, Y.T. A Dead-Beat-Controlled Fast-Transient-Response Buck Converter with Active PseudoCurrent-Sensing Techniques. IEEE Trans. Very Large Scale Integr. (VLSI) Syst. 2019, 27, 1751-1759. [CrossRef]

6. Hwang, Y.S.; Chen, J.J.; Ku, Y.T.; Yang, J.Y. An Improved Optimum-Damping Current-Mode Buck Converter with Fast-Transient Response and Small-Transient Voltage Using New Current Sensing Circuits. IEEE Trans. Ind. Electron. 2021, 68, 9505-9514. [CrossRef]

7. Chen, W.W.; Chen, J.F.; Liang, T.J.; Wei, L.C.; Ting, Y.W. Designing a Dynamic Ramp with an Invariant Inductor in Current-Mode Control for an On-Chip Buck Converter. IEEE Trans. Power Electron. 2014, 29, 750-758. [CrossRef]

8. Saini, D.K.; Reatti, A.; Kazimierczuk, M.K. Average Current-Mode Control of Buck DC-DC Converter with Reduced Control Voltage Ripple. In Proceedings of the IECON 2016 42nd Annual Conference of the IEEE Industrial Electronics Society, Florence, Italy, 23-26 October 2016.

9. Zhong, S.; Shen, Z. A Hybrid Constant On-Time Mode for Buck Circuits. Electronics 2021, 10, 930. [CrossRef]

10. Lin, Y.-C.; Chen, C.-J.; Chen, D.; Wang, B. A Ripple- Based Constant On-Time Control with Virtual Inductor Current and Offset Cancellation for DC Power Converters. IEEE Trans. Power Electron. 2012, 27, 4301-4310. [CrossRef] 
11. Nien, C.-F.; Chen, D.; Hsiao, S.-F. A Novel Adaptive Quasi-Constant On-Time Current-Mode Buck Converter. IEEE Trans. Power Electron. 2017, 32, 8124-8133. [CrossRef]

12. Nguyen, V.H.; Huynh, H.A.; Kim, S.Y.; Song, H. Active EMI Reduction Using Chaotic Modulation in a Buck Converter with Relaxed Output LC Filter. Electronics 2018, 7, 254. [CrossRef]

13. Chen, W.C.; Chen, H.C.; Chien, M.W.; Chou, Y.W.; Chen, K.H.; Lin, Y.H.; Lee, C.C. Pseudo-constant switching frequency in on-time controlled buck converter with predicting correction techniques. IEEE Trans. Power Electron. 2016, 31, 3650-3662. [CrossRef]

14. Chen, W.C.; Lin, K.L.; Chen, K.H.; Lin, Y.H.; Tsai, T.Y.; Huang, C.C.; Yang, C.C. A pseudo fixed switching frequency 2 kHz/A in optimum on-time control buck converter with predicting correction technique for EMI solution. In Proceedings of the 2014 IEEE International Symposium on Circuits and Systems (ISCAS), Melbourne, Australia, 1-5 June 2014; pp. 946-949.

15. Zhen, S.; Zeng, P.; Chen, J.; Zhou, W.; Wang, J.; Luo, P.; Zhang, B. Transient Response Improvement of DC-DC Converter by Current Mode Variable on Time Control. In Proceedings of the 2018 IEEE 61st International Midwest Symposium on Circuits and Systems (MWSCAS), Windsor, ON, Canada, 5-8 August 2018.

16. Lin, H.-C.; Fung, B.-C.; Chang, T.-Y. A current mode adaptive on-time control scheme for fast transient DC-DC converters. In Proceedings of the 2008 IEEE International Symposium on Circuits and Systems, Seattle, WA, USA, 18-21 May 2008.

17. Zhen, S.; Zhou, S.; Zeng, L.; Yang, M.; Ming, X.; Luo, P.; Zhang, B. Variable on time controlled buck converter for DVS applications. In Proceedings of the IECON 2017-43rd Annual Conference of the IEEE Industrial Electronics Society, Beijing, China, 29 October-1 November 2017.

18. Bari, S.; Li, Q.; Lee, F.C. Fast Adaptive On Time Control for Transient Performance Improvement. In Proceedings of the IEEE Applied Power Electronics Conference and Exposition (APEC), Charlotte, NC, USA, 15-19 March 2015.

19. Liu, P.-J.; Kuo, M.-H. Adaptive On-Time Buck Converter with Wave Tracking Reference Control for Output Regulation Accuracy. Energies 2021, 14, 3809. [CrossRef]

20. Tsai, C.H.; Chen, B.M.; Li, H.L. Switching Frequency Stabilization Techniques for Adaptive On-Time Controlled Buck Converter with Adaptive Voltage Positioning Mechanism. IEEE Trans. Power Electron. 2016, 31, 443-451. [CrossRef]

21. Bari, S.; Li, Q.; Lee, F.C. A New Fast Adaptive On-Time Control for Transient Response Improvement in Constant On-Time Control. IEEE Trans. Power Electron. 2018, 33, 2680-2689. [CrossRef]

22. Aiello, O.; Fiori, F. A new mirroring circuit for power MOS current sensing highly immune to EMI. Sensor 2013, $13,1856-1871$. [CrossRef] [PubMed]

23. Min, R.; Chen, C.; Zhang, X.; Zou, X.; Tong, Q.; Zhang, Q. An Optimal Current Observer for Predictive Current Controlled Buck DC-DC Converters. Sensors 2014, 14, 8851-8868. [CrossRef]

24. Tong, Q.; Chen, C.; Zhang, Q.; Zou, X. A Sensorless Predictive Current Controlled Boost Converter by Using an EKF with Load Variation Effect Elimination Function. Sensors 2015, 15, 9986-10003. [CrossRef]

25. Aiello, O.; Fiori, F. Current sensing circuit for DC-DC converters based on the miller effect. In Proceedings of the 2013 International Conference on Applied Electronics (AE), Pilsen, Czech Republic, 10-11 September 2013; pp. 1-4.

26. Sheehan, R. Understanding and Applying Current-Mode Control Theory. Texas Instruments Technical Document Application Reports. Literature Number: SNVA555. 2007. Available online: https://www.ti.com/lit/pdf/snva555 (accessed on 31 August 2021).

27. Chen, J.J.; Hwang, Y.S.; Ku, Y.T.; Li, Y.H.; Chen, J.A. A Current-Mode-Hysteretic Buck Converter with Constant-FrequencyControlled and New Active-Current-Sensing Techniques. IEEE Trans. Power Electron. 2021, 36, 3126-3134. [CrossRef]

28. Chen, J.-J. An Active Current-Sensing Constant-Frequency HCC Buck Converter using Phase-Frequency-Locked Techniques. IEEE Trans. Ultrason. Ferroelectr. Freq. Control 2008, 55, 761-769. [CrossRef]

29. Aiello, O. Hall-Effect Current Sensors Susceptibility to EMI: Experimental Study. Electronics 2019, 8, 1310. [CrossRef]

30. Aiello, O.; Fiori, F. A New MagFET-Based Integrated Current Sensor Highly Immune to EMI. Elsevier Microelectron. Reliab. 2013, 53, 573-581. [CrossRef]

31. Ouyang, Y.; He, J.; Hu, J.; Wang, S.X. A current sensor based on the giant magnetoresistance effect: Design and potential smart grid applications. Sensors 2012, 12, 15520-15541. [CrossRef]

32. Jantaratana, P.; Sirisathitkul, C. Low-cost sensors based on the GMI effect in recycled transformer cores. Sensors 2008, 8, 1575-1584. [CrossRef] [PubMed]

33. Dalessandro, L.; Karrer, N.; Kolar, J.W. High-Performance Planar Isolated Current Sensor for Power Electronics Applications. IEEE Trans. Power Electron. 2007, 22, 1682-1692. [CrossRef]

34. Song, C. Accuracy Analysis of Constant-On Current-Mode DC-DC Converters for Powering Microprocessors. In Proceedings of the 2009 Twenty-Fourth Annual IEEE Applied Power Electronics Conference and Exposition, Washington, DC, USA, 21 March 2009.

35. Zhang, H.J. Modeling and Loop Compensation Design of Switching Mode Power Supplies. LINEAR Technology Application Note 149, January 2015. Available online: https://www.analog.com/media/en/technical-documentation/application-notes/an1 49fa.pdf (accessed on 31 August 2021).

36. Li, J.; Lee, F.C. New modeling approach and equivalent circuit representation for current-mode control. IEEE Trans Power Electron. 2010, 25, 1218-1230. 
37. Enrique, J.-M.; Barragán, A.-J.; Durán, E.; Andújar, J.-M. Theoretical Assessment of DC/DC Power Converters' Basic Topologies. A Common Static Model. Appl. Sci. 2018, 8, 19. [CrossRef]

38. Suntio, T. Dynamic Modeling and Analysis of PCM-Controlled DCM-Operating Buck Converters-A Reexamination. Energies 2018, 11, 1267. [CrossRef]

39. Ridley, R.B. An Accurate and Practical Small-Signal Model for Current-Mode Control. Available online: www.ridleyengineering. com (accessed on 1 September 2021).

40. Li, J. Current-Mode Control: Modeling and Its Digital Application. Ph.D. Dissertation, Virginia Polytechnic Institute and State University, Blacksburg, VA, USA, 2009.

41. Jiang, C.R.; Chai, C.C.; Han, C.X.; Yang, Y.T. A high performance adaptive on-time controlled valley-current-mode DCDC buck converter. J. Semicond. 2020, 41, 062406. [CrossRef] 